\title{
Resistant profile of Staphylococcus aureus to commonly prescribed antibacterial agents in patients with urinary tract infection.
}

\author{
*Izebe, K. S'; Ibrahim, K'; Oladosu, P'.Abdulrahim, \\ E. M. Aniagu, S.O ${ }^{2}$; and Ekpenyong, M. ${ }^{3}$, \\ 'Department of Pharmaceutical Microbiology, Human Virology \& Biotechnology \\ ${ }^{2}$ Department of Pharmacology and Toxicology, \\ ${ }^{3}$ NIPRD Clinic, \\ National Institute for Pharmaceutical Research and Development (NIPRD) \\ P.M.B. 21, Garki Abuja.
}

\begin{abstract}
Four thousand two hundred and fifty (4250) patients that attended NIPRD Clinic over a period of four years from 2000 to 2004, with clinical symptoms of urinary tract infection (UTI) were screened for possible pathogens. Staphylococcus aureus, Streptococcus sp, Escherichia coli and coliforms were the commonly encountered organisms. The antibiogram was determined using commercially prepared antibiotic disc diffusion method on the urinary pathogens. Staphylococcus aureus $(36.5 \%)$ was the predominant pathogens, followed by Streptococcus sp. (10.1\%). A combination of Escherichia coli and other coliforms gave 8.0\%. Among the antibacterial agents recommended for the treatment of these organisms, the 4-quinolones (ciprofloxacin and ofloxacin) were the most effective, with $95.5 \%$ of the isolates being sensitive. The drug resistance profile of Staphylococcus aureus showed high resistant patterns with the 4- quinolone $(5.0 \%)$, gentamicin $(46 \%)$, cephalosporin $(64 \%)$, ampicillin ( $83 \%)$, nalidixic acid (84\%) amoxicillin and nitrofurantoin (89\%), tetracycline $(93 \%)$, and penicillin $(95 \%)$.
\end{abstract}

Key words: pathogens, antibiotics, resistance, urinary tract infection

\section{Introduction}

The pathogens associated in urinary tract infections (UTI) are diverse in pathogenicity (Edington et al 1976; Derrick, 1982). These uropathogens cause cystitis; pyelonephritis and more than ninety per cent of these pathogens are part of the intestinal flora (Cruickshank, et al 1980). In UTI, women are frequently infected than men (Cheesebourgh, 1991) and are usually the sources of nosocomial infections (Hugo et al 1998). The predominant pathogens vary from one location to the other. Akerele et al (2000) reported that Staphylococcus aureus was predominant bacterium and constituted $36 \%$ of the organism isolated from urine. Escherichia coli were reported as the commonest cause of UTI (Hugo et al 1998, Cruickshank et al 1980). The recommended drugs of choice for treating pathogens from urine include ampicillin, cotrimoxazole, nalidixic acid, nitrofurantoin, sulphonamide and kanamycin (Cruickshank et al 1980). Akelele et al (2000) reported that cephalosporins and 4- quinolone were most frequently used drugs in the treatment of uropathogens and that resistance of bacteria to these antibiotics has been on the increase. Obot (1999) reported that the resistance of bacteria in urine to nalidixic acid and ciprofloxacin of $0.2 \mu \mathrm{g} / \mathrm{ml}$ has been

\footnotetext{
* Corresponding Author:
} 
chromosomally mediated.

In this work, we try to establish the prescription pattern of drugs used in the treatment of UTI, the predominant pathogen isolated and its resistant profile.

\section{Material and methods}

\section{Patients}

4250 patients attending National Institute for Pharmaceutical Research Development (NIPRD) Clinic (Abuja., Nigeria) with complaints of UTI were recruited into the study. Mid-stream urine was collected from each patient in sterile universal container.

\section{Culture Media}

Nutrient and MacConkey agar (Biotec) were prepared according to the manufacturer's manual. Blood agar was prepared by adding $2.0 \mathrm{ml}$ of whole blood into $18 \mathrm{ml}$ of molten nutrient agar maintained at $55^{\circ} \mathrm{C}$, mixed and poured into sterile Petri dish and allowed to set.

\section{Antibiotic Disc}

Commercially prepared discs (Mast Diagnostics Mast Group UK,) include. Cephalosporins (30ig), Gentamicin (10ig), 4-quinolone (5ig), Erythromycin (10 $\mu \mathrm{g})$, Tetracycline (30ig), Co-trimoxazole (30ig), ampiclox (30ig), Ampicillin (30ig), Penicillin (10U), Nalidixic Acid (30ìg), Amoxicillin (30ig), Streptomycin (10ig), Rifampicin (15ìg), Chloramphenicol (30ig) and Nitofurantoin (300ig) were used.

\section{Prescription Rate}

The frequency of prescription was determined by the antibacterial agent that showed a zone of inhibition of between $18-24 \mathrm{~mm}$.

\section{Urine Culture}

The patients were each given a sterile urine container and instructed to collect early morning, mid-stream urine, and the sample to reach the laboratory within thirty minutes of collection. The urine was aseptically inoculated into blood and MacConkey agar plates. All inoculated plates were incubated at $37^{\circ} \mathrm{C}$ for 18 hours. The plates were observed for growth. The bacterial colonies were identified by biochemical and serological tests (8) (3). The antibiotic disc was each applied on the isolates.

\section{Statistical Method:}

Percentage and mean were used to analyze the data.

\section{Result.}

The frequency at which the uropathogens were isolated is shown in Table 1. Staphylococcus aureus was the most frequently isolated organism $(36.3 \%)$. This was followed by Streptococcus sp and Escherichia coli with 10.1 and $8.0 \%$ respectively. Klebsiella sp had $2.30 \%$ frequency of isolation, while Proteus sp and Coliforms had $2.10 \%$ each. Candida albicans and Pseudomonas sp had the least frequency of isolation of 2.10 and $1.70 \%$ 
respectively. There was no pathogen isolated from 36.6 per cent of the patients. Also 5 to $20 \%$ of the patients had more than one organism isolated from them.

The types and frequency of use of the various antibacterial agents in treating UTI is shown in Table II. The cephalosporin (Cefuroxine, Ceftazidime And Cefotaxime) were found to be used most frequently with $13.71 \%$ prescription. The Gentamicin and Ampicillin were found to follow with 12.41 and $11.6 \%$ respectively. The 4- quinolone and Nalidixic Acid had 8.9 and $5.8 \%$ prescription rate respectively. The least prescribed antibacterial agent was Rifampicin with less than $1.0 \%$ prescription rate

The resistance profile of Staphylococcus aureus to different antibacterial agents is shown in Table 3. The percentage of resistance to Nitrofurantoin, Penicillin, and Tetracycline was $89.0,96.0$ and $93.0 \%$ respectively. The resistant profile of Staphylococcus aureus to Gentamicin was $46.0 \%$ while 4 - quinolone had the least resistance of $5.0 \%$. The resistant profile for other pathogens isolated from UTI patients was not studied.

TABLE 1: Isolated pathogens from urine samples

\begin{tabular}{|l|l|l|}
\hline Pathogens & Frequency & $\%$ Frequency \\
\hline Staphylococcus aureus & 1540 & 36.30 \\
Streptococcus sp & 430 & 10.10 \\
Escherichia coli & 340 & 8.00 \\
Klebsiella sp & 100 & 2.30 \\
Proteus sp & 90 & 2.10 \\
Coliforms & 90 & 2.10 \\
Candida albicans & 70 & 1.70 \\
Pseudomonas sp & 20 & 0.50 \\
Mixed flora & 220 & 5.20 \\
No pathogens & 1340 & 31.6 \\
\hline
\end{tabular}

TABLE II: The frequency of prescription of antibacterial agents.

\begin{tabular}{|l|l|l|}
\hline Antimicrobial agents & Frequency & $\%$ frequency \\
\hline Cephalosporins & 2850 & 13.71 \\
Gentamicin & 2580 & 12.41 \\
Ampicillin & 2420 & 11.60 \\
Streptomycin & 1860 & 8,95 \\
4-quinolones & 1850 & 8.90 \\
Erythromycin & 1640 & 7.89 \\
Tetracycline & 1210 & 7.36 \\
Nalidixic acid & 2580 & 5.82 \\
Amoxicillin & 1190 & 5.72 \\
Nitrofurantoin & 700 & 4.18 \\
Penicillin & 810 & 3.90 \\
Cotrimoxazole & 700 & 3.37 \\
Chloramphenicol & 600 & 2.89 \\
Ampiclox & 500 & 2.41 \\
Rifampicin & 180 & 0.87 \\
\hline
\end{tabular}

Table III: Resistant profile of St aphylococcus aureus to antibacterial agents

\begin{tabular}{|l|l|}
\hline- & Percéntage Resistánce \\
\hline 4-quminolone & 5.0 \\
Gentamicin & 46.0 \\
Cephalosporins & 64.0 \\
Ampicillin & 83.0 \\
Nalidixic & 84.0 \\
Amoxicillin & 89.0 \\
Nitrofurantoin & 89.0 \\
Tetracycline & 93.0 \\
Pénicillin & 95.0 \\
\hline
\end{tabular}




\section{Discussion}

The most frequently isolated bacterium from the four thousand two hundred and fifty patients was Staphylococcus aureus with 36.3 per cent. Akerele et al (5) reported that Staphylococcus aureus was the predominant pathogen from urine with 36.65 per cent in Benin City. About 31.6 per cent of patients had no pathogens isolated. The gross resistance of Staphylococcus aureus to Nalidixic acid (84\%) and Nitrofurantoin (89\%), the traditional drugs of choice for UTI gave a cause for concern. Other authors have attributed these resistant profiles to these antibacterial agents as a result of the followings: route of administration, frequency of dosing, patients' compliance and high number of substandard and cheap drugs. The 4-quinolones (Ciprofloxacin and Ofloxacin) had been the most effective of all the antibacterial agents against the Uropathogens with just 5.0 per cent resistance. The 4-quinolones are new class of antimicrobial agents, and were derived from precursor molecule called Nalidixic acid (8). The relatively high cost of the drug and low patronage has contributed to less abuse.

Abuja, a metropolitan city with a growing and teaming population, has had the health and social amenities over stretched. Therefore, there is the tendency for gross drug abuse hence this pattern of drug resistance. The health sector should have to put in place comprehensive antibiotic or drug policy, monitor drug distribution, usage and finally restricted dispensing. There is also the need to intensify the public enlightenment of drug usage and consequences associated with drug abuse.

\section{Acknowledgement}

The epidemiology study of resistant profile of Staphylococcus aureus to commonly prescripted antibacterial agents in UTI patients was conducted with NIPRD colleagues. The Diagnostic Units (NIPRD Clinic) provided the enabling environment. I appreciate the advice and correction of the manuscript of the write up by senior colleagues. I appreciated the contribution of medical teams to the study.

\section{Reference:}

(1) Edington, G.M. and Giles, H. M. (1976). Pathology in Tropics. $2^{\text {nd }}$ Ed. Edward Arnold publishers Limited London. Pp260-321.

(2) Derrick, F. C. (1982). Urinary Tract Infections in adults, a guide to treatment Post Grad Med. 72: 281 288.

(3) Cruickshank, J. P.; Marimoin, R. H. and Swain, H. A. (1980). Medical Microbiology 12th Ed. Churchill Livingstone Edinburgh vol. Il pp190-204.

(4) Cheesebrough, M. (1991). Medical Laboratory manual for Tropical Countries Vol II microbiology $3^{\text {rd }}$ Ed. -University Press Ltd. Britain pp 148.

(5) Hugo, W.B. and Russell, A. O. (1998). Pharmaceutical Microbiology. $6^{\text {th }}$ Ed. Blackwell Science Ltd. London. $\mathrm{Pp} 137$.

(6) Akerele, J; Ahonkhai, I.; Isah, A. (2000). Urinary pathogens and Antibacterial susceptibility: A Retrospective study of Private Diagnostic laboratories in Benin. Nigerian Journal of medical Laboratory Science $12 \mathrm{pp} 144$.

(7) Obot, M. J.; Obaseiki-Ebor, E. E. and Ekanemessang, A. C. (1999). Susceptibility Pattern of Bacterial isolates to 4-Quinolones Antibacterial. Nigerian Journal of Microbiology 13 No 1-2 pp 1-5.

(8) Baker, F. J. and Breach, M. R. (1980). Medical Microbiology Techniques. Butterworth, London pp 536.

(9) Nickel, J.C. (1990). The battle of bladder in the pathogenesis and treatment of uncomplicated cystitic. International Urogynecological Journal . I: 212-222. 